\title{
Los cambios de gobierno en Argentina y Brasil y sus efectos en las políticas públicas de educación superior
}

Argentina y Brasil son las naciones de mayor extensión territorial del Cono Sur y, junto con México, poseen las economías más grandes de América Latina. Ambos países cuentan también con grandes sistemas de educación superior y varias de sus universidades se encuentran entre las principales Instituciones de Educación Superior (IES) de Iberoamérica, según las clasificaciones internacionales más reconocidas (ARWU, 2020).

Sin embargo, al lado de estas coincidencias también coexisten diferencias considerables. Argentina es el país latinoamericano con una de las mayores tasas de cobertura en educación superior de la región, mientras que Brasil tiene una tasa inferior al $50 \%$ frente a una población mucho más grande. Más aún, la mayor proporción de la matrícula estudiantil en Argentina asiste a universidades e IES del sector público, en tanto que en Brasil la mayor parte de los estudiantes de nivel universitario acude a instituciones particulares, pero en ambas naciones la mayor parte de la investigación en las disciplinas científicas, sociales y humanísticas se realiza en las universidades públicas.

En 2019, con casi un año de diferencia, tomaron posesión nuevos regímenes políticos en Brasil (enero) y Argentina (diciembre). Ambos países han conseguido fortalecer sus sistemas democráticos en las últimas décadas, después de haber pasado -hasta antes de la década de los 80 del siglo pasado- por diversos periodos de regímenes autoritarios. Como suele suceder en las democracias con elecciones libres, en estas dos naciones ha habido alternancias en el poder entre opciones opuestas.

En el caso argentino, el reemplazo reciente fue de una opción política progresista frente a una conservadora, y en el brasileño, un candidato ultraconservador derrotó al representante de una coalición de izquierda. Esos cambios de gobierno han modificado de manera sustantiva las políticas de educación superior, principalmente en el sector público, pues aunque los dos países guardan enormes diferencias políticas, ambos enfrentan enormes desafíos económicos, los cuales se agudizarán seguramente a causa de la recesión económica previsible por los efectos de la pandemia.

Conocer y reflexionar los efectos de los cambios políticos y socioeconómicos derivados de los estos acontecimientos es un asunto de interés para los estudiosos y los interesados en la educación superior. Cabe señalar que en el caso argentino, el panorama de las políticas públicas de educación superior es menos claro que en el brasileño, donde los cambios ya han ocurrido de una manera más clara, desde hace más tiempo y se puede observar que han ido a contrapelo de las que habían sido implementadas por 
los regímenes anteriores, principalmente las que habían sido desarrolladas durante poco más de 12 años de gobiernos del PT.

Los textos que integran este dossier han sido escritos por destacados especialistas en la educación superior, profesores e investigadores de distintas universidades e instituciones de enseñanza superior de los países en cuestión que examinan las políticas que se están implementando en cada uno de los dos países, al igual que sus perspectivas. Para una mejor comprensión de los procesos estudiados, se han agrupado por país y, además, se revisan primero los que corresponden a Brasil, por ser este país en donde primero se llevó a cabo la transición política.

En el primer texto, Joao Ferreira de Oliveira y Nelson Cardoso Amaral hacen una revisión de las transiciones políticas y económicas en Brasil, principalmente en el periodo posterior al proceso de la destitución (impeachment) de la presidenta Dilma Rousseff, en 2016. Su análisis del proceso los lleva a concluir que la agenda ultraneoliberal enarbolada por el actual presidente, Jair Bolsonaro, constituye una defensa férrea de la libertad económica y del capitalismo financiero. Esta agenda, argumentan, está asociada con una perspectiva autoritaria y conservadora que se contrapone a la construcción democrática y participativa de la sociedad brasileña y al concepto de Estado que surgió de la redemocratización del país, plasmado en gran parte en la Constitución Federal de 1988.

El trabajo escrito por Mario Luiz Neves de Azevedo y Afranio Mendes Catani se centra en la propuesta para el sector educativo de nivel superior planteada por el actual gobierno, conocida como FUTURE-SE. Consideran que este programa tiene una profunda orientación "gerencialista", la cual concuerda con las políticas de educación superior que se han venido desarrollando desde la década de los 90. Con base en la perspectiva de Pierre Bourdieu, los autores argumentan que la educación superior de su país se debe entender como un campo social, espacio de luchas y contradicciones, al tiempo que es un sector estratégico para la construcción de la cultura, el desarrollo en todos los ámbitos y un derecho fundamental para el avance de la democracia y la ciudadanía.

El tercer trabajo de esta sección, elaborado por Luis Enrique Aguilar y Eliacir Neves França, debate en torno a las políticas educativas iniciadas por Jair Bolsonaro. Los autores señalan que las acciones de ese gobierno han significado la intensificación de los ajustes ultraliberales que desmantelan una parte importante de los derechos sociales, la esfera pública, con el apoyo del Congreso Nacional, sobrevalorando al sector privado.

Por lo que corresponde al caso argentino, Martín Unzué comienza revisando de manera amplia el sistema de educación superior y algunos de los momentos históricos en los que las dictaduras militares reprimieron a las universidades, más adelante hace un recuento detallado de las principales acciones y políticas emprendidas por el gobierno conservador de Mauricio Macri (2015-2019), frente a las universidades y diversas instancias públicas de investigación. Respecto al actual gobierno, encabezado por Alberto Fernández, el autor vislumbra algunos de los cambios y estrategias de acción, a partir de algunas propuestas e iniciativas iniciadas, todo esto sin grandes expectativas en virtud de los devastadores efectos de la emergencia sanitaria. 
En otro trabajo del apartado sobre Argentina, Anabella Lucardi plantea que, del análisis de las líneas de políticas públicas para la educación superior anunciadas por el presidente Alberto Fernández, parece haber la intención de dar continuidad al proceso de democratización de la universidad impulsado en el periodo 2003-2015. Por último, subraya que la gran incertidumbre que atraviesa el sector universitario, obligado a migrar enteramente a una modalidad de educación mediada por tecnologías, demanda creatividad y capacidad de gestión por parte de los tomadores de decisiones en políticas públicas e institucionales.

El texto que cierra esta sección, elaborado por Silvia Llomovatte y Judith Naidorf, es un recuento detallado de las acciones legislativas y ejecutivas que ha llevado a cabo el nuevo gobierno. Si bien las autoras señalan que muy poco tiempo después de haber tomado posesión el régimen del presidente Alberto Fernández se tuvieron que realizar medidas de emergencia en todo el país ante el avance de la COVID-19, aplazando la implementación de algunas de las transformaciones en el sistema de educación superior y universitaria, así como en diversos organismos de ciencia, tecnología e innovación, destacan que las expectativas hacia el nuevo gobierno siguen intocadas, no obstante reconocen que las graves consecuencias económicas de la pandemia harán difícil que los cambios anunciados alcancen su plenitud en el corto plazo.

Como puede verse, este conjunto de trabajos a cargo de distinguidos académicos de ambos países, alentados y promovidos por los cambios políticos, ofrecen un panorama amplio y detallado de las transformaciones que están ocurriendo en la educación superior.

Armando Alcántara Santuario, coordinador. Investigador titular del Instituto de Investigaciones sobre la Universidad y la Educación, UNAM

\section{Referencia}

Academic Ranking of World Universities (ARWU) www.shangairanking.com. Consultada el $30 / 08 / 2020$ 